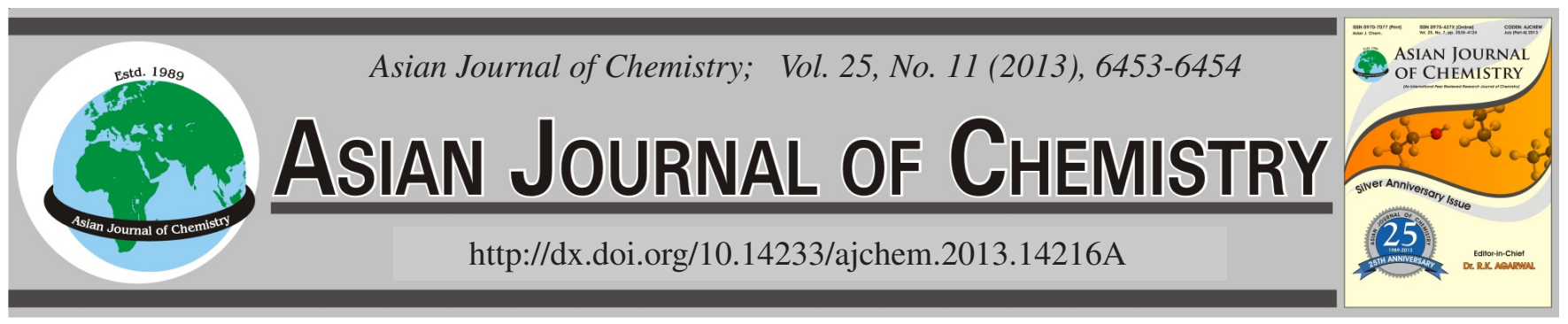

NOTE

\title{
Reductimetric Determination of Peroxydisulphate with Iron(II) in Phosphoric Acid Medium Using Resorufin as a Redox Indicator
}

\author{
K. ViJAYA RAJU* and T. RAMBABU
}

Department of Engineering Chemistry, College of Engineering, Andhra University, Visakhapatnam-530 003, India

*Corresponding author: E-mail: vijayarajukurimella@gmail.com

(Received: 20 June 2012;

Accepted: 14 May 2013)

AJC-13493

\begin{abstract}
A simple, accurate and direct reductimetric titration method has been developed for the determination of peroxydisulphate or persulphate using iron(II) as reductant in high phosphoric acid medium $(9 \mathrm{M})$, employing resorufin as a redox indicator. The colour transition of the indicator at the end-point (from red to blue-green) is sharp and reversible. Persulphate in the range 15-50 has been determined with an accuracy of $\pm 0.6 \%$. The precision of the method has been determined by computing the pooled standard deviation $(0.06 \mathrm{mg})$ and $95 \%$ confidence limits. In this method persulphate is rapidly and quantitatively reduced to sulphate in a two electron reduction step while resorufin is reduced to its corresponding semiquinone in a one electron reduction step by iron(II). The formal redox potentials of the oxidant system [persulphate/sulphate couple] and those of the reductant system [iron(III)/iron(II) couple] (under the optimum titration conditions) and the transitional potential of the indicator have been measured. Based on these potentials data, the conditions need in the titration have been offered. The interferences due to diverse ions has been studied.
\end{abstract}

Key Words: Peroxydisulphate, Iron(II), Phosphoric acid, Resorufin.

Persulhate is known to be one of the most common oxidizing agents in analytical chemistry and finds its applications in the analysis of several inorganic and organic substances ${ }^{1-3}$. The methods so for reported for its determination are not only limited in number but also indirect, because the direct reactions are too slow. These methods generally involve the addition of a known excess of a standard reductant solution (as well as a catalyst if necessary) such as arsenic(III) ${ }^{2,4}$, oxalic $\operatorname{acid}^{1}$ (silver sulphate catalyst), vanadium(II) $)^{2,5}$, hydroquinone ${ }^{3,6}$ [silver(I) catalyst], iron(II $)^{1-3,7-10}$ [in presence of small amounts of $\mathrm{H}_{3} \mathrm{PO}_{4}, \mathrm{HF}$ or $\mathrm{NaBr}$ ], iodide ${ }^{3,11}$ and back titrating the excess with a suitable oxidant such as bromate, permanganate, cerium(IV) etc. In the case of iodometric method ${ }^{3,11}$ however, the liberated iodine is titrated against thiosulphate. In some of the methods a known excess of iron(II) is added and the iron(III) formed is titrated against mercury(I) nitrate ${ }^{9}$ or ascorbic acid ${ }^{10}$. A few direct potentiometric and visual methods involving iron(II) as a reductant ${ }^{12-14}$ and in presence of a catalyst such as iodine- silver(I)-erothrysin $\mathrm{B}^{12}$; iodine monochloride (chloroform used as indicator) ${ }^{13}$ or in $10 \mathrm{M}$ phosphoric acid medium (cacotheline or some thiazine group of dyes used as redox indicators $)^{14}$ were also reported.
From a perusal of the literature, it may be seen that most of the methods are indirect and need the use of expensive catalysts. Even the direct titrimetric procedures ${ }^{12,13}$ also suffer from the same disadvantage. The direct titrimetric methods ${ }^{14}$ carried out in phosphoric acid medium suffer from the drawback that inert atmosphere must be maintained during the titration, to prevent the aerial oxidation of the reduced dye obtained at the end-point by reduction with iron(II). Recently we investigated the use of resorufin as an advantageous a redox indicator ${ }^{15,16}$ especially in the reductimetric determinations carried out in phosphoric acid medium using iron(II) as a reductant.

The present paper describes the reductimetric determination of persulphate or peroxydisulhate using iron(II) as a reductant in phosphoric acid medium and employing resorufin as an advantageous redox indicator. The procedure now developed does not suffer from any of the drawbacks of the earlier methods. Further, the present method offers the advantage over the similar method reported earlier ${ }^{14}$ in that the colour transition of the indicator at the end-point (red to blue-green) is sharp, it can be easily detected and no inert atmosphere need be maintained during the titration, because the blue-green reduced product of the indicator, resorufin, obtained at the end-point is found stable to atmospheric oxidation for $6 \mathrm{~min}^{15}$. 
Iron(II) solution: About $0.05 \mathrm{M}$ solution of iron(II) was prepared in $0.5 \mathrm{~N}$ sulphuric acid medium and standardized ${ }^{2}$.

Peroxydisulphate or persulphate solution: About 0.025 $\mathrm{M}(0.05 \mathrm{~N})$ solution of peroxydisulphate solution was prepared from an AR grade sample and standardised ${ }^{2}$.

Resorufin (RSF) solution: A $0.05 \%(\mathrm{w} / \mathrm{v})$ resorufin solution was prepared in distilled water from resorufin sample supplied by Aldrich (USA).

Orthophosphoric acid: Orthophosphoric acid of AR grade was utilized in the investigation.

A DPM voltmeter was used for potential measurements. A bright platinum rod and a saturated calomel electrode were used as indicator and reference electrodes, respectively. A ' $U$ ' tube having porous end glass plates and filled with saturated $\mathrm{KCl}$ was used as a salt bridge.

Recommended procedure: To an aliquot (3-10 mL) of persulphate $(0.05 \mathrm{~N})$ solution taken in a 150 beaker, required volume of orthophosphoric acid was added to give an acid strength of $9 \mathrm{M}$ towards the end-point. The solution was now bubbled with purified carbon dioxide gas to expel any dissolved oxygen and 4-5 drops the indicator solution (resorufin) added. The reaction mixture was now titrated against a $0.05 \mathrm{~N}$ iron(II) solution on a magnetic stirrer to the sharp colour transition of the indicator from red to blue-green. The end-point colour transition of the indicator is sharp and reversible. Some of the typical results obtained by the recommend procedure have been shown in Table-1.

\begin{tabular}{|c|c|c|c|c|}
\hline \multicolumn{5}{|c|}{$\begin{array}{l}\text { TABLE-1 } \\
\text { REDUCTIMETRIC DETERMIATION OF PERSULPHATE } \\
\text { WITH IRON(II) IN PHOSPHORIC ACID MEDIUM }\end{array}$} \\
\hline \multicolumn{2}{|c|}{$\begin{array}{l}\text { Peroxydisulphate } \\
\text { found* }(\mathrm{mg})\end{array}$} & \multirow{2}{*}{$\begin{array}{c}\text { Pooled } \\
\text { standard } \\
\text { deviation } \\
(\mathrm{Sg}) \\
(\mathrm{mg})\end{array}$} & \multirow{2}{*}{$\frac{1.96 \times \mathrm{Sg}}{\sqrt{\mathrm{n}}}$} & \multirow{2}{*}{$\begin{array}{l}95 \% \text { Confidence } \\
\text { limits (mg) } \\
\overline{\mathrm{x}} \pm \frac{1.96 \times \mathrm{Sg}}{\sqrt{\mathrm{n}}}(\mathrm{mg})\end{array}$} \\
\hline $\begin{array}{l}\text { Reference } \\
\text { Method }^{2}\end{array}$ & $\begin{array}{l}\text { Author's } \\
\text { Method }\end{array}$ & & & \\
\hline 14.40 & 14.48 & \multirow{4}{*}{0.06} & \multirow{4}{*}{0.05} & $14.43-14.53$ \\
\hline 24.00 & 24.09 & & & $24.04-24.14$ \\
\hline 33.60 & 33.46 & & & $33.41-33.51$ \\
\hline 48.00 & 48.18 & & & $48.13-48.23$ \\
\hline
\end{tabular}

Persulphate in the range of $15-50 \mathrm{mg}$ have been determined by the recommended procedure. The accuracy of the method is found to be $\pm 0.06 \%$. The precision of the method expressed in the form of pooled standard deviation and $95 \%$ confidence limits have also been included (Table-1).

Rao and Sagi ${ }^{17}$ stated that the formal redox potential of iron(III)/iron(II) couple decreases considerably (from 680 to $400 \mathrm{mV}$ ) in phosphoric acid medium (12 M) and thus iron(II) functions as powerful reductant in this acid medium. Therefore, the reduction of persulphate has been investigated with iron(II) in phosphoric acid medium. In order to explain the conditions needed in the titration, the author has measured the formal redox potentials of the oxidant system [persulphate/ sulphate couple] and the reductant system [iron(III)/iron(II) couple] by mixing the equimolar solutions of perslphate and sulphate solutions in the case of the former and iron(III) and
iron(II) solutions in the latter and measuring the potentials of each system at $9 \mathrm{M}$ phosphoric acid medium as described by Rao and Dikshitulu ${ }^{18}$. The potentials, thus measured, are found to be $1050 \pm 10$ and $429 \pm 10 \mathrm{mV}$, respectively for the oxidant and reductant systems. Thus, there is a difference in potential of $620 \mathrm{mV}$ between the two systems and it is sufficient to bring rapid reduction of persulphate by iron(II).

To explain the suitability of resorufin as a redox indicator in the present redox system, the author has measured the transition potential of the indicator adopting the procedure described by Belcher et al. ${ }^{19}$ and it is found to be $710 \pm 10 \mathrm{mV}$. The transition potential of the indicator $(710 \mathrm{mV})$ is found to be intermediate between the formal potential of the oxidant $(1050$ $\mathrm{mV})$ and reductant $(429 \mathrm{mV})$ systems. Thus, these potentials data neatly explain the conditions needed in the titration.

In this determination persulphate is reduced by iron(II) to sulfate in a two electron reduction step. The indicator resorufin, however, is reduced by iron(II), at the end-point, to its semiquinone form which is blue-green in colour, in a one electron reduction step as elucidated in our earlier communication $^{15}$.

Interferences: A study of interference due to diverse ions has been carried out and found that large amounts of chloride, sulphate, zinc(II), aluminum(III) and mercury(II) ions do not interfere. The colours of chromium(III), nickel(II) and cobalt(III) do not interfere when less than $0.8,4.0$ and $0.3 \mathrm{mg}$, respectively are present per $\mathrm{ml}$ of the reaction mixture. However, nitrate and nitrite ions interfere at all concentrations.

\section{ACKNOWLEDGEMENTS}

The authors express their grateful thanks to Dr. G.D. Sudhakar for his valuable contributions in culmination of the paper and to U.G.C. (New Delhi) for granting Emeritus Fellowship to K. Vijaya Raju.

\section{REFERENCES}

1. Vogel's Text Book of Quantitative Chemical Analysis, Longmans, London, edn. 5, pp. 374, 384 (1989).

2. I.M. Kolthoff and R. Belcher, Volumetric Analysis, Interscience Publishers, Vol. 3, pp. 75,80,112, 177, 240, 509, 625, 629 (1957).

3. A. Berka, J. Vulturin and J. Zyka, Newer Redox Titrations, Pergamon Press, London, pp. 151, 164, 176, 194 (1965).

4. E. Rupp and G. Siebler, Pharm. Zentralhalle, 66, 193 (1925).

5. Y. Yoshida, J. Chem. Soc. (Japan), 59, 49 (1938).

6. O. Rottova and J. Zyka, Coll. Czech. Chem. Commun., 24, 2809 (1959).

7. I.M. Kolthoff and E.M. Carr, Anal. Chem., 25, 298 (1953).

8. J.H. Vander Meulen, Rec. Trav. Chim., 58, 553 (1939).

9. R. Belcher and T.S. West, Anal. Chim. Acta, 5, 360 (1951).

10. L. Erdey, I. Buzas and K. Vigh, Periodica Polytechnol., 3, 1 (1959); Chem. Abstr., 53, 16804 (1959)

11. A. Kurtenacker and H. Kubina, Z. Anal. Chem. Chem., 83, 14 (1930).

12. F. Sierra and E. Manzon, An. Real. Soc. Espan. Fisica. Quim., 63, 51 (1967).

13. A.B. Singh and A.N. Singh, J. Indian Chem. Soc., 35, 508 (1958).

14. N.K. Murthy, V. Satyanarayana and Y.P. Rao, Talanta, 24, 757 (1977).

15. K.V. Raju, G.D. Sudhakar and T.B. Patrudu, Asian J. Chem., 19, 683 (2007).

16. K.V. Raju, Asian J. Chem., 23, 1690 (2011).

17. G.G. Rao and S.R. Sagi, Talanta, 9, 715 (1962).

18. G.G. Rao and L.S.A. Dikshitulu, Talanta, 10, 295 (1963).

19. R. Belcher, A. Nutton and W.I. Stephen, J. Chem. Soc., 3857 (1952). 